\title{
Genetic studies of Polish migraine patients: screening for causative mutations in four migraine-associated genes
}

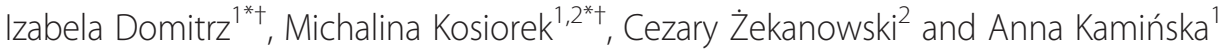

\begin{abstract}
Background and aim: Migraine is the most common neurological disorder, affecting approximately $12 \%$ of the adult population worldwide, caused by both environmental and genetic factors. Three causative genes have been identified in familial hemiplegic migraine (FHM) families: CACNA1A, ATP1A2, and SCNA1A. Recently, several mutations in KCNK18 have also been found as causative factors in migraine development. The aim of our study was to identify the genetic background of migraine in the Polish population.
\end{abstract}

Material and methods: Sixty patients with migraine without aura $(\mathrm{MO})$ or with different types of migraine with aura (MA), including sporadic hemiplegic, familial hemiplegic, and probable familial hemiplegic, were screened for mutations in the four genes previously linked with different types of migraine (ATP1A2, CACNA1A, SCN1A, and KCNK18).

Results: Two missense mutations were found. One novel mutation in SCN1A, encoding a subunit of sodium channel, causing amino acid change M1500V localized to a region encoding inactivation loop between transmembrane domains III and IV of the channel, was detected in a female FHM patient. The M1500V mutation was absent in a group of 62 controls, as well as in the ExAC database. The second, already known missense mutation S231P in KCNK18 was found in a female MA patient. Additionally, a novel intronic polymorphism possibly affecting alternative splicing of SCN1A, at chr2:16685249, g.77659T>C, and c.4581+32A>G, located between exons 24 and 25, in a region encoding the inactivation loop of the sodium channel was found in a female MO patient. No mutations in ATP1A2 or CACNA1A were found in the study group.

Conclusions: The presence of SCN1A mutations and absence of mutations in ATP1A2 or CACNA1A suggest that the Polish patients represent FHM type 3. On the other hand, the presence of KCNK18 mutation indicated another FHM subtype. It could be speculated that contrary to other European populations, the genetic basis of migraine in the Polish population involves mutations in genes not included in the study. Next-generation sequencing methods should be implemented to identify other migraine-associated variants.

Keywords: Familial hemiplegic migraine, Aura migraine, SCN1A, KCNK18, Missense mutations, Splice variants, SNP, Genetic background

\section{Introduction}

Migraine is the most common neurological disorder, affecting approximately $12 \%$ of the adult population worldwide, caused by both environmental and genetic factors. Its heritability is estimated at ca. $40-70 \%$. Numerous linkage studies and candidate-gene studies have

\footnotetext{
*Correspondence: idomitrz@wum.edu.pl; mkosiorek@imdik.pan.pl †'Equal contributors

'Department of Neurology, Warsaw Medical University, 61 Żwirki i Wigury Street, 02-091 Warsaw, Poland

Full list of author information is available at the end of the article
}

identified causative genes in migraine without aura (MO) and migraine with aura (MA). Three such genes have been identified in familial hemiplegic migraine (FHM). The first FHM type (FHM1; MIM141500) is related to locus 19p13 and caused by mutations in $C A C N A 1 A$, encoding alpha 1A subunit of voltage-dependent calcium channel type $\mathrm{P} /$ Q (MIM601011) [1]. Mutations in CACNA1A contribute also to episodic ataxia (EA2; MIM108500) [2] and spinocerebellar ataxia type 6 (SCA6; MIM183086) [3]. The second FHM type (FHM2; MIM602481) is caused by mutations in ATP1A2 encoding alpha 2 subunit of $\mathrm{Na}+\mathrm{K}+-$ 
ATPase (MIM182340) [4]. Finally, the third FHM locus (FHM3; MIM609634) is at 2q24, and the implicated gene SCNA1A (MIM182389) encodes $\alpha$ subunit of the neuronal voltage-gated $\mathrm{Na}+$ channel [5]. Mutations in $S C N 1 A$ were also recognized as a cause of epilepsy [6]. Recently, KCNK18 at locus 10q25.3, encoding K+ channel subfamily $\mathrm{K}$ member 18, has been found to be connected with FHM classified as other than types 1, 2, and 3 (MIM613655) [7]. Other studies have provided evidence on the influence of the genetic variants of SLC6A4 encoding a serotonin transporter on a migraine occurrence [8]. Moreover, recent genome-wide association studies (GWAS) have identified four novel genetic variants associated with migraine [9]: rs1835740 modulating glutamate homeostasis and specific for migraine with aura; rs11172113 implicating lipoprotein receptor LRP1, which may interact with neuronal glutamate receptors; rs10166942 in close proximity to TRPM8, encoding a cold and pain sensor; and rs2651899 in PRDM16, with an unclear role [9]. All these variants only confer a small to moderate risk for migraine, which concurs with migraine being a heterogeneous disorder [9]. A list of single nucleotide polymorphisms in 10 genes was reported in a large German case-control cohort study of migraine with aura [10], and recently, several genetic variants in APOA1BP, TBC1D7, FUT9, STAT6, ATP5B, AJAP1, TSPAN2, FHL5, C7orf10, and MMP16 have been found in GWAS performed in Western Europe [11].

To identify the genetic background of migraine in Polish patients, we screened ATP1A2, CACNA1A, SCN1A, and KCNK18 for mutations in a group of 60 patients with migraine without aura or with different types of aura migraine: typical, sporadic hemiplegic and familial hemiplegic or probable familial hemiplegic. All patients were Caucasians of Polish origin.

\section{Materials and methods Ethics statement}

Written consent was obtained from probands, diagnosed family members, and probands' relatives according to the Declaration of Helsinki [12]. The genetic study was approved by the Ethics Committee of the Medical University of Warsaw (Warsaw, Poland) in compliance with the national legislation and the Code of Ethical Principles for Medical Research Involving Human Subjects of the World Medical Association.

\section{Patients' clinical description}

Sixty patients (47 women and 13 men), mean age $48 \pm$ 13 years, of the Headache Outpatient Clinic and Neurological Department, with different types of migraine diagnosed according to the International Headache Society (IHS) criteria, 3rd edition [13], were analyzed. The study group consisted of several subgroups: 4 families (Table 1-4a, b, c; 7a, b, c; 43a, b, c, d; 47a, b, c) with familial hemiplegic migraine (FHM3 families) and sporadic hemiplegic migraine (SHM1 family), 6 patients with probable familial hemiplegic migraine (F?HM-families of patients with hemiplegic migraine not seen), 7 patients with sporadic hemiplegic migraine (SHM), 11 patients with MA, and 23 patients with MO. Two members from FHM family no. 7 were also diagnosed with epilepsy with grand mal attacks (father and older son). One patient diagnosed SHM also had mental retardation. One patient with $\mathrm{MO}$ also had episodic ataxia (EA). Family no. 43 was examined for the presence of mutations in Leiden factor $\mathrm{V}$. This analysis revealed the presence of the variant G1691A, c.1746G>A p.Arg534Gln, rs6025 in this family and in one family member (mother) was possibly associated with ischemic stroke. The study was performed at the Institute of Hematology and Blood Transfusion in Warsaw, according to standard protocols based on Sanger sequencing. Only the family 43 was examined for Leiden factor $\mathrm{V}$ genetic variants, and these tests were part of routine diagnostic practice at the Institute of Hematology and Blood Transfusion in Warsaw and were made available under standard medical care. The migraine patients were interviewed and examined in the Headache Outpatient Clinic or at the Department of Neurology of Warsaw Medical University. The diagnosis was performed by an experienced neurologist. Duration of the disease ranged between 1 and 40 years (mean duration $21+11$ years), and the frequency of migraine attacks ranged between 1 attack/1 week to 1 attack/12 months. Patient profile is presented in Table 1. As a control group, we used our existing database of 62 samples of whole-exome sequencing, which were screened for the presence of identified variants.

\section{Sanger sequencing}

Genomic DNA was extracted from peripheral blood leukocytes using standard salting-out method. Exons 4, 5, 13, $16,17,24,26,29,32$, and 36 of CACNA1A, exons 6, 14, $15,16,18,20,23,24$, and 26 of SCNA1A, exons 9, 16, 17, 18,19 , and 22 of $A T P 1 A 2$, and exons 1, 2, and 3 of KCN1K18 (all with flanking intronic sequences) were sequenced using automated, fluorescent sequencing method. Genes and the exons were chosen on the basis of the frequencies of known migraine-causing mutations (Leiden Familial Hemiplegic Migraine Variation Database). In brief, the amplicons were amplified with Master Mix Kit and Hot Start Master Mix Kit (Qiagen) using genomic DNA from each patient. Primers were designed using Primer Premier software (Additional file 1). The annealing temperature of $58{ }^{\circ} \mathrm{C}$ was applied for all primers. Exon 26 of SCN1A and exon 3 of KCNK18 were amplified in overlapping fragments. Resulting amplicons were purified with Exonuclease I/FastAP (Fermentas) and sequenced using ABI PRISM 3130 Genetic Analyzer (Applied Biosystems) 
Table 1 Clinical phenotypes and polymorphisms in migrainerelated genes (SCN1A, CACNA1A, ATP1A2, KCNK18) in the study group

\begin{tabular}{|c|c|c|c|c|}
\hline ID & $\begin{array}{l}\text { Year of } \\
\text { birth }\end{array}$ & Sex & Clinical phenotype & SCN1A, CACNA1A, ATP1A2, KCNK18 \\
\hline 1 & 1980 & M & MA & \\
\hline 2 & 1976 & $\mathrm{~F}$ & $\mathrm{~F} ? \mathrm{HM}$ & $\begin{array}{l}\text { c.4498A>G, p.M1500V, } \\
\text { rs376885324 (ex. } 24 \text { SCN1A) }\end{array}$ \\
\hline 3 & 1978 & $\mathrm{~F}$ & MA & rs2298771 (ex. 16 SCN1A) \\
\hline $4 a$ & 1952 & $\mathrm{~F}$ & FHM & rs17846715 (ex. 16 ATP1A2) \\
\hline $4 b$ & 1978 & $\mathrm{~F}$ & FHM & \\
\hline $4 c$ & 1980 & $\mathrm{~F}$ & FHM & \\
\hline 5 & 1967 & $\mathrm{~F}$ & $\mathrm{MO}$ & \\
\hline 6 & 1967 & $\mathrm{~F}$ & $\mathrm{MO}$ & \\
\hline $7 a$ & 1954 & M & $F H M+E P I$ & \\
\hline $7 b$ & 1982 & M & $\mathrm{FHM}+\mathrm{EPI}$ & $\begin{array}{l}\text { rs2298771 (ex. } 16 \text { SCN1A), } \\
\text { rs16012 (ex. } 13 \text { CACNA1A) }\end{array}$ \\
\hline $7 c$ & 1984 & M & $\mathrm{MO}$ & rs2298771 (ex. 16 SCN1A) \\
\hline 8 & 1980 & M & SHM & \\
\hline 9 & 1958 & $\mathrm{~F}$ & $\mathrm{~F} ? \mathrm{HM}$ & \\
\hline 10 & 1944 & $\mathrm{~F}$ & $\mathrm{MO}$ & $\begin{array}{l}\text { Novel intronic polymorphism } \\
\text { c. } 4581+32 A>G \text {, between } \\
\text { ex. } 24 \text { and } 25\end{array}$ \\
\hline
\end{tabular}

$111946 \quad F \quad M O$

$121954 \quad F \quad M O$

131982 F MA

141966 F $\quad M O$

$\begin{array}{llll}15 & 1962 \quad M \quad M O\end{array}$

161972 F MA

$\begin{array}{llll}17 & 1962 & \text { M } & \text { MO } \\ 18 & 1968 & \text { F } & \text { MO } \\ 19 & 1943 & \text { F } & \text { MO } \\ 20 & 1963 & \text { F } & \text { F?HM } \\ & & & \\ 21 & 1957 & \text { F } & \text { F?HM } \\ 22 & 1978 & \text { F } & \text { MO } \\ 23 & 1968 & \text { F } & \text { MA } \\ 24 & 1934 & \text { F } & \text { MO } \\ 25 & 1960 & F & \text { MO } \\ 26 & 1953 & \text { F } & \text { MA } \\ 27 & 1973 & \text { F } & \text { SHM } \\ 28 & 1977 & \text { F } & \text { F?HM } \\ 29 & 1988 & \text { M } & \text { SHM }+ \text { MR } \\ 30 & 1969 & \text { F } & \text { F?HM } \\ 31 & 1973 & \text { F } & \text { SHM } \\ 32 & 1976 & \text { M } & \text { MO } \\ 33 & 1987 & \text { F } & \text { SHM }\end{array}$

rs2298771 (ex. 16 SCN1A)

rs2298771 (ex. 16 SCN1A)

rs2298771 (ex. 16 SCN1A)

rs16012 (ex. 13 CACNA1A)

rs41276894 (ex. 4 CACNA1A)

rs61734524 (ex. 9 ATP1A2)

rs17846715 (ex. 16 ATP1A2)

rs2298771 (ex. 16 SCN1A)

rs17846715 (ex. 16 ATP1A2),
Table 1 Clinical phenotypes and polymorphisms in migrainerelated genes (SCN1A, CACNA1A, ATP1A2, KCNK18) in the study group (Continued)

\begin{tabular}{|c|c|c|c|c|}
\hline 34 & 1970 & $\mathrm{~F}$ & MO & rs2298771 (ex. 16 SCN1A) \\
\hline 35 & 1972 & $\mathrm{~F}$ & $\mathrm{MO}$ & \\
\hline 36 & 1968 & $\mathrm{~F}$ & MO & \\
\hline 37 & 1966 & $\mathrm{~F}$ & MA & rs2298771 (ex. 16 SCN1A) \\
\hline 38 & 1969 & $\mathrm{~F}$ & MA & \\
\hline $39 a$ & 1988 & $\mathrm{~F}$ & MO & \\
\hline $39 b$ & 1960 & $\mathrm{~F}$ & $\mathrm{MO}$ & \\
\hline 40 & 1970 & $\mathrm{~F}$ & MO & \\
\hline 41 & 1974 & $\mathrm{~F}$ & MO & \\
\hline 42 & 1958 & $\mathrm{~F}$ & MO & \\
\hline $43 a$ & 1989 & M & $\begin{array}{l}\text { MO (mutation in } \\
\text { Leiden factor } V \text { ) }\end{array}$ & $\begin{array}{l}\text { rs61734524 (ex.9 ATP1A2), } \\
\text { rs16016 (ex. } 16 \text { CACNA1A) }\end{array}$ \\
\hline $43 b$ & 1994 & $\mathrm{~F}$ & $\begin{array}{l}\text { FHM (mutation in } \\
\text { factor } V \text { Leiden) }\end{array}$ & rs61734524 (ex.9 ATP1A2) \\
\hline $43 c$ & 1970 & $\mathrm{~F}$ & $\begin{array}{l}\text { FHM (mutation in } \\
\text { factor V Leiden) }\end{array}$ & $\begin{array}{l}\text { rs61734524 (ex.9 ATP1A2), } \\
\text { rs16016 (ex. } 16 \text { CACNA1A) }\end{array}$ \\
\hline $43 d$ & 1950 & M & $\begin{array}{l}\text { Ischemic stroke } \\
\text { (mutation in factor } \\
\text { V Leiden), mother } \\
\text { with FHM + MA }\end{array}$ & \\
\hline 44 & 1958 & $\mathrm{~F}$ & $\mathrm{MO}+\mathrm{EA}$ & \\
\hline 45 & 1960 & $\mathrm{~F}$ & MA & \\
\hline $46 a$ & 1943 & $\mathrm{~F}$ & SHM mother & rs61734524 (ex. 9 ATP1A2) \\
\hline $46 b$ & 1984 & M & SHM & Not tested \\
\hline $46 c$ & 1943 & M & SHM father & \\
\hline 47 & 1962 & $\mathrm{~F}$ & MA & rs17846715 (ex. 16 ATP1A2) \\
\hline 48 & 1967 & M & SHM & \\
\hline 49 & 1963 & $\mathrm{~F}$ & MA & \\
\hline 50 & 1972 & $\mathrm{~F}$ & SHM & $\begin{array}{l}\text { rs61734524 (ex. } 9 \text { ATP1A2), } \\
\text { rs17846715 (ex. } 16 \text { ATP1A2) }\end{array}$ \\
\hline 51 & 1959 & $\mathrm{~F}$ & MA & rs2298771 (ex. 16 SCN1A) \\
\hline
\end{tabular}

Description of clinical phenotype: $E A$, episodic ataxia, Epi epileptic seizures, $F$ ?HM probable familial hemiplegic migraine, FHM familial hemiplegic migraine, $M A$ migraine with typical aura, $M O$ migraine without aura, $M R$ mental retardation, SHM sporadic hemiplegic migraine rs41288127 (ex. 22 ATP1A2) with the BigDye Terminator v1.1 Cycle Sequencing Kit (Applied Biosystems).

\section{Results \\ SCN1A}

Among the 60 Polish patients studied, we found a single nucleotide polymorphism c.4498A $>$ G, rs376885324, in exon 24 of $S C N 1 A$ leading to amino acid substitution M1500V (Fig. 1a). This variant was found in a female FHM patient and had not been linked to an FHM clinical phenotype before (see Table 2). The family history of the patient suggested autosomal dominant inheritance pattern, and according to clinical interview, seven members of 


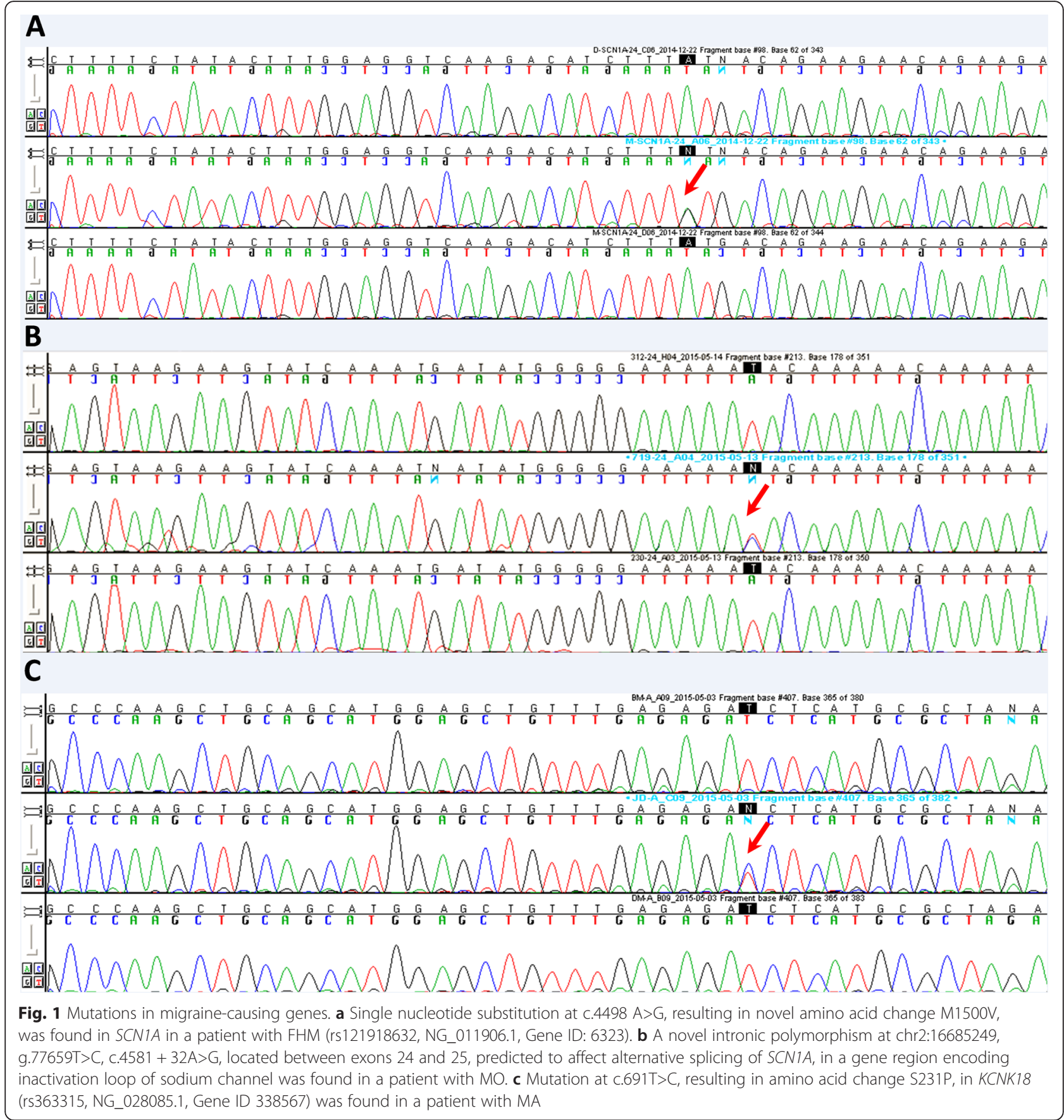

the proband's family were also affected by migraine, including a sister, the father, two father's brothers, a cousin, and the grandmother (Fig. 2). Unfortunately, the material for genetic testing from other family members was unavailable, but the patient's sister and father were examined clinically and diagnosed with FHM in our clinic.

Bioinformatic assessment using PolyPhen-2 HumDiv [14] showed that the M1500V variant is probably damaging with a score of 0.982 (sensitivity, 0.75; specificity, 0.96). According to the Protein Variation Effect Analyzer
(PROVEAN) and Sorting Intolerant From Tolerant (SIFT) tools $[15,16]$, the variant is damaging (score -3.68) and deleterious (score 0.001). The MutationTaster prediction tool [17] also describes the variant as disease-causing. M1500V was not detected in our 62 controls or in the ExAC database, which contains data for the genomic region of interest from 60,000 DNA samples, including more than 30,000 samples from European populations. However, the mutation is present in the Ensembl database with a frequency of 1:8593. 
Table 2 Clinical phenotype of FHM patient with mutation M1500V in exon 24 of SCN1A

\begin{tabular}{ll}
\hline Hemiplegic migraine (HM) onset (years) & 22 \\
Triggering factors of HM & Emotional stress \\
Hemiplegia during aura phase & + \\
Sensory disturbances during aura phase & + \\
Visual disturbances during aura phase & + \\
Aphasia during aura phase & + \\
Aura duration (min) & 60 \\
Headache duration (h) & $4-24$ \\
Side of headache and hemiplegia & Bilateral_-variable sides \\
Character & Pulsating \\
Nausea/vomiting/photophobia/phonophobia & $+/-/-/-$ \\
during migraine attack & \\
Other types of headache & MO, MA \\
\hline
\end{tabular}

In addition to the M1500V mutation, we identified several synonymous single nucleotide polymorphisms in SCN1A in the study group and one missense variant at chr2:166892788, g.37362G>A, c.3199G >A, rs2298771, which the frequency of occurrence, according to data from the dbSNP database, is $24 \%$, and in our study group was $20 \%$ (in 12 patients with different phenotypes), resulting in amino acid change A1067T (Table 1, Fig. 3). According to PROVEAN and SIFT, this amino acid substitution is neutral with a score of -0.068 , and according to PolyPhen-2 mutation, is benign with a score of 0.000 . The MutationTaster scored the variant as a neutral polymorphism that might change protein feature. This variant has been assigned to myoclonic astatic epilepsy phenotype [18], which is in accordance with our study showing its presence in one family (no. 7; three patients, $5 \%$ of the study group) with epilepsy and FHM.
In a female patient with migraine without aura and with onset at puberty, we found a novel intronic polymorphism possibly affecting alternative splicing of $S C N 1 A$, at 2:166852491, g.77659T>C, c.4581+32A > G, located between exons 24 and 25 , in a region encoding inactivation loop of the channel (Fig. 1b). The patient had migraine with a typical course: high-intensity attacks lasting for a few hours with frequency 1 per month. The patient's familial history is surprising. Her two sisters were diagnosed with a probable CADASIL (cerebral autosomal dominant arteriopathy with subcortical infarcts and leukoencephalopathy), but with no mutation in NOTCH3. One of the sisters suffered from dementia and was diagnosed with disseminated and diffuse changes in brain MRI interpreted as the beginning of demyelination (she died at the age of 60 years, and no medical records were available). The patient's mother died at the age of 69 , likely from a stroke. The patient's father and brother and the patient's siblings' children are healthy. The variant could not be evaluated by the PROVEAN, SIFT, or Poly-Phen2 tools due to a lack of data. This variant is absent in the ExAC database, but insertion A/AT has been found at this nucleotide position (http://exac.broadinstitute.org/region/2166852491-166852491), with a frequency of ca. 0.000008 . The substitution reported here could be a novel rare intronic variant. According to the MutationTaster, the variant could alter various protein features, including domains and motifs, downstream of the altered splice site, as presented in Table 3.

\section{CACNA1A and ATP1A2}

We found several synonymous single nucleotide polymorphisms in the CACNA1A and ATP1A2 genes, as summarized in a Table 1 .

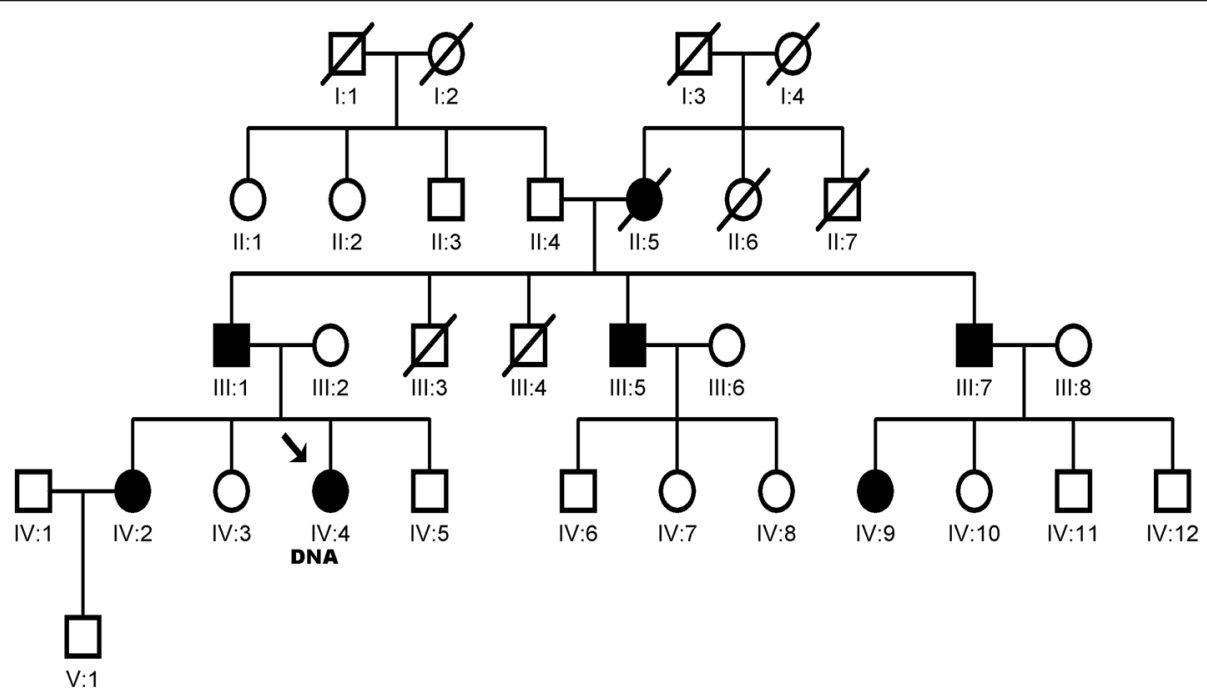

Fig. 2 Pedigree of FHM patient with M1500V mutation in exon 24 of SCN1A 


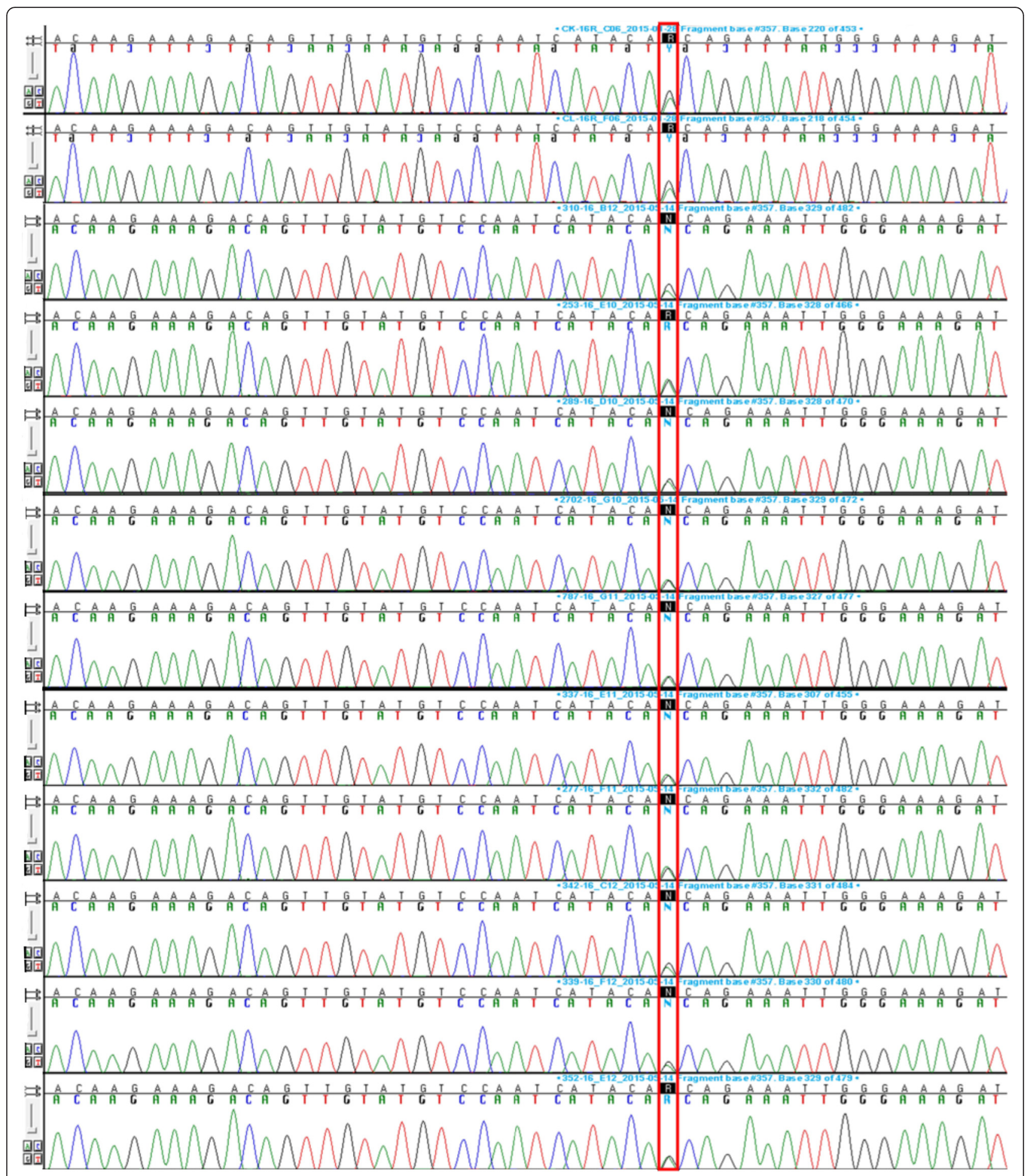

Fig. 3 A1067T mutation in SCN1A. Exon 16 with flanking intronic regions of SCN1A gene was analyzed as described in the "Materials and methods" section. The missense variant at chr2:166892788, g.37362G>A, c.3199G >A, rs2298771 resulting in amino acid change A1067T found in 12 patients with different phenotypes (20\% of the study group) and present at the high frequency of $24 \%$ in dbSNP database is indicated by frame 
Table 3 Predicted loss of protein features downstream of the splice site altered by c.4581+32A>G variant in SCN1A

\begin{tabular}{llll}
\hline Start (aa) & End (aa) & Feature & Details \\
\hline 1523 & 1821 & Repeat & IV \\
1537 & 1537 & Conflict & F ->L (in [7]; CAA46439/M91803). \\
1537 & 1560 & Transmem & Helical; name = S1 of repeat IV; (by similarity). \\
1572 & 1595 & Transmem & Helical; name = S2 of repeat IV; (by similarity). \\
1602 & 1625 & Transmem & Helical; name = S3 of repeat IV; (by similarity). \\
1636 & 1657 & Transmem & Helical; voltage sensor; name = S4 of repeat IV; (by similarity). \\
1673 & 1695 & Transmem & Helical; name = S5 of repeat IV; (by similarity). \\
1762 & 1786 & Transmem & Helical; name = S6 of repeat IV; (by similarity). \\
1788 & 1788 & Carbohyd & N-linked (GlcNAc...) (potential). \\
1915 & 1944 & Domain & IQ \\
\hline
\end{tabular}

\section{KCNK18}

We identified a known mutation at c.691T>C, rs363315, in exon 3 of $K C N K 18$ gene leading to amino acid substitution S231P in a female patient diagnosed with migraine with aura (Fig. 1c).

Additionally, in our study group, one family (no. 43; four patients, $6.6 \%$ of the study group) had mutation in Leiden factor $\mathrm{V}$, associated with blood clots. In this family, we did not find any mutations in SCNA1A, CACN1A, KCNK18, and $A T P 1 A 2$ reported before as migraine-causing.

\section{Discussion}

Migraine is the most common neurological disorder with a well-defined genetic background, but until now, no migraine-causing mutations have been studied in Polish patients $[19,20]$. For genetic screenings in this study, we have selected exons 4, 5, 13, 16, 17, 24, 26, 29, 32 , and 36 of CACNA1A; exons $6,14,15,16,17,23,24$, and 26 of SCNA1A; exons 9, 16, 17, 18, 19, and 22 of ATP1A2; and exons 1, 2, and 3 of KCN1K18 (all with flanking intronic sequences). We have selected these genetic regions according to the frequencies of found disease-causing genetic variants stated in Leiden Familial Hemiplegic Migraine Variation Database and to the highest probability of genetic variant occurrence.

Overall, our study sheds the first light on the genetic background of migraine in the group of Polish patients, and we believe that this study will help us to stratify our pool of patients in terms of their genetic status of the most common variants of the four genes associated with migraine for future large-scale genetic studies.

We have identified a novel FHM-linked M1500V mutation in $S C N 1 A$, putatively affecting the inactivation loop of the sodium channel protein and confirming previous reports found the S231P mutation in KCNK18 in a patient with migraine with aura. Surprisingly, no disease-causing variants in $A T P 1 A 2$ and $C A C N A 1 A$ were found in the study group.
The novel mutation M1500V substitutes evolutionarily highly conserved methionine residue in sodium channel protein type 1 subunit alpha (P35498). The functionally important amphipathic methionine involved in playing binding/recognition of hydrophobic ligand methionine is substituted with hydrophobic valine with a largely nonreactive aliphatic side chains and packed in the protein interior. There is no direct data indicating that M1500V is causally linked to the disease, but it localizes next to the known F1499L mutation (dbSNP:rs121918632), involved in episodes of elicited repetitive daily blindness (ERDB) co-segregating with familial hemiplegic migraines [21] and with I1498M [22]. The Met > Val substitution is in the IFM motif responsible for fast channel inactivation, located in the inactivation intracellular gate between domains III and IV, each composed of six transmembrane segments called S1-S6 (Fig. 4). Since normal fast inactivation of the channel results from occlusion of the intracellular part of the channel by a short loop between domains III and IV, mutation in this region could disturb the inactivation. For example, in oocyte expression studies, $\mathrm{R} 1648 \mathrm{H}$ accelerated recovery from inactivation, W1204R shifted the voltage-dependence of activation and inactivation in the negative direction, R859C shifted the voltage-dependence of activation in the positive direction, and T875M enhanced slow inactivation [23]. The alterations due to $\mathrm{R} 1648 \mathrm{H}$ and W1204R are predicted to increase sodium channel activity and neuronal excitability, whereas those due to $\mathrm{R} 859 \mathrm{C}$ and T875M should decrease the channel activity and neuronal excitability [23]. Further, in vitro studies are necessary to assess the impact of the M1500V mutation on sodium channel inactivation.

The second mutation we found is S231P in KCNK18. This mutation has already been well characterized and shown to be migraine-related but not to influence the activity of the TRESK K2P potassium channel encoded by KSNK18 [24]. Other studies on this variant also showed relationship to migraine with typical aura [25]. 


\section{a subunit}

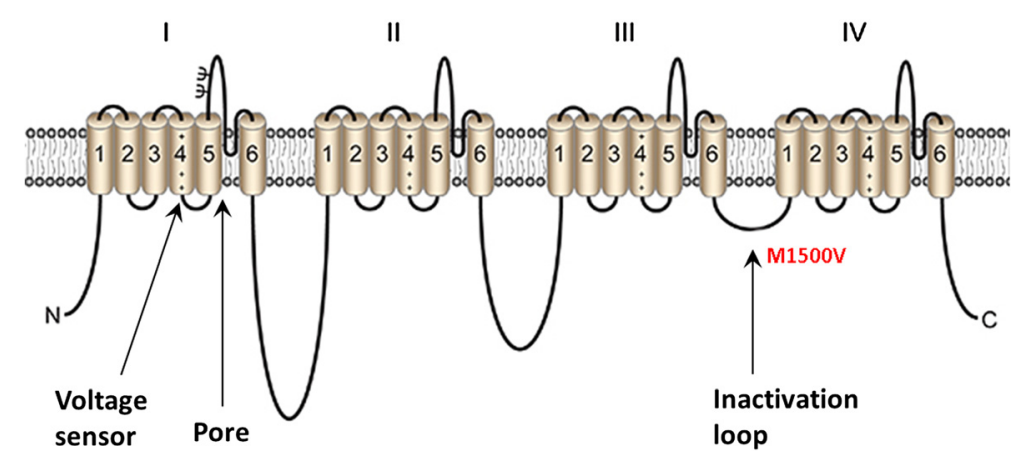

Fig. 4 Transmembrane organization of sodium channel a subunit. The alpha subunit of the channel comprises four repeat domains (I-IV), each containing six membrane-spanning segments (1-6). The highly conserved segment 4 acts as the voltage sensor of the channel close to the pore for ion entry. After $\mathrm{Na}+$ has entered the cell and the membrane's potential reached its maximum, the channel inactivate by closing the inactivation loop. Mutation M1500V could abolish channel inactivation and lead to its constitutive activity and firing of the synapses; however, further functional studies are needed to verify this assumption. Adapted from Brackenbury and Isom [29]

Accordingly, we found the KCNK18 mutation in a patient with migraine without aura.

The novel intronic polymorphism identified in a family with a CADASIL-like phenotype and migraine could affect the splicing of SCN1A transcript. According to the MutationTaster, this variant may influence splicing (e.g., increase or gain of splice donor site at position g.77658) and affect protein features (for details, see Table 3). Voltage-dependent inactivation of $\mathrm{Na}+$ channels is a consequence of voltage-dependent activation, and an inactivated $\mathrm{Na}+$ channel enters a non-conducting and nontransmitting signals state, as the inactivation gate, the cytoplasmic loop linking domains III and IV of the $\alpha$ subunit, obstructs the open pore [26]. Due to its the location in the exon 24, encoding the inactivation loop, the variant seems likely to produce a constitutively inactive form of sodium channel alpha subunit leading to the permanent shut down of synaptic transmission. Detailed functional studies are needed to elucidate the link between generation of various alternative splicing forms and biological pathomechanisms and clinical phenotype of migraine.

Additionally, based on our studies, it could be speculated that the factor Leiden $\mathrm{V}$ mutation found in one family carrying no causative mutations in $S C N A 1 A$, $C A C N 1 A$, KCNK18, or ATP1A2 is a sole cause of migraine with aura and vision disability and strokes in that family, in line with several reports showing a linkage between migraine and Leiden factor variants [27, 28].

\section{Future perspectives}

We suggest that mutations located in other parts of the analyzed genes or in other genes, not yet shown to be connected with migraine, cause various clinical forms of the disease in the Polish population. We postulate that nextgeneration sequencing (NGS) methods, e.g., whole-exome sequencing or whole-genome sequencing, should be used to identify comprehensively migraine-causative mutations. This is reinforced by the fact that recent large-scale studies from European populations have provided an extensive list of susceptibility genes linked to migraine. The list of candidate genes linked with FHM occurrence includes: APOA1BP, TBC1D7, FUT9, STAT6, ATP5B, AJAP1, TSPAN2, FHL5, C7orf10, and MMP16 [11].

\section{Additional file}

Additional file 1: Primers for selected exons of CACNA1A, SCN1A, ATP1A2 and KCNK18 gene designed using Primer Premier software. (DOCX $23.2 \mathrm{~kb}$ )

\section{Competing interests}

The authors declare that they have no competing interests.

Authors' contributions

ID, MK, CZ, and AK conceived and designed the study. ID, MK, CZ, and AK drafted and revised the manuscript. ID and MK performed the data analysis. ID and AK collected the samples. MK performed RT-PCR and sequencing experiments. All authors read and approved the final manuscript.

\section{Acknowledgements}

This study was supported by the statutory grant from the Ministry of Science and Higher Education to the Department of Neurology, Medical University of Warsaw. The funders had no role in the study design, data collection, and analysis; decision to publish; or preparation of the manuscript. The authors would like to acknowledge help with the DNA preparation and sharing WES data for the control group comparison, made by Małgorzata Kobryś and Jakub Fichna, respectively.

\section{Author details}

${ }^{1}$ Department of Neurology, Warsaw Medical University, 61 Żwirki i Wigury Street, 02-091 Warsaw, Poland. Department of Neurodegenerative Disorders, Mossakowski Medical Research Centre PAS, 5 Pawinskiego Street, 02-106 Warsaw, Poland. 
Received: 3 September 2015 Accepted: 23 December 2015

Published online: 08 January 2016

\section{References}

1. Ophoff RA, Terwindt GM, Vergouwe MN, van Eijk R, Oefner PJ, Hoffman SM, et al. Familial hemiplegic migraine and episodic ataxia type-2 are caused by mutations in the Ca2+ channel gene CACNL1A4. Cell. 1996;87:543-52.

2. Denier C, Ducros A, Durr A, Eymard B, Chassande B, Tournier-Lasserve E, et al. Missense CACNA1A mutation causing episodic ataxia type 2. Arch Neurol. 2001;58:292-5.

3. Pietrobon D. CaV2.1 channelopathies. Pflugers Arch. 2010:460:375-93.

4. Gallanti A, Cardin V, Tonelli A, Bussone G, Bresolin N, Mariani C et al. The genetic features of 24 patients affected by familial and sporadic hemiplegic migraine. Neurol Sci.

2011;32 Suppl 1:S141-2.

5. Dichgans $M$, Freilinger $T$, Eckstein BE, Babini E, Lorenz-Depiereux B, Biskup $S$ et al. Mutation in the neuronal voltage-gated sodium channel SCN1A in familial hemiplegic migraine. Lancet. 2005:366:371-7.

6. Meisler MH, Kearney JA. Sodium channel mutations in epilepsy and other neurological disorders. J Clin Investig. 2005;115:2010-7.

7. Lafrenière RG, Cader MZ, Poulin JF, Andres-Enguix I, Simoneau M, Gupta N et al. A dominant-negative mutation in the TRESK potassium channel is linked to familial migraine with aura. Nat Med. 2010;16:1157-60.

8. Hamel E. Serotonin and migraine: biology and clinical implications. Cephalalgia. 2007;27:1293-300

9. Schürks M. Genetics of migraine in the age of genome-wide association studies. J Headache Pain. 2012:13:1-9.

10. Todt U, Netzer C, Toliat M. New genetic evidence for involvement of the dopamine system in migraine with aura. Hum Genet. 2009:125:265-79.

11. Anttila V, Winsvold BS, Gormley P, Kurth T, Bettella F, McMahon G, North American Brain Expression Consortium, UK Brain Expression Consortium, International Headache Genetics Consortium, et al. Genome-wide metaanalysis identifies new susceptibility loci for migraine. Nat Genet. 2013;45: 912-7.

12. Style Matters: Statements from the Vancouver Group. http://dx.doi.org/10. 1136/bmj.302.6786.1194. BMJ 1991; 302:1194

13. The International Classification of Headache Disorders, 3rd edition (beta version) Part one: the primary headaches. Cephalalgia 2013;33(9):644-658.

14. Adzhubei I, Jordan DM, Sunyaev SR. Predicting functional effect of human missense mutations using PolyPhen-2. In: Curr Protoc Hum Genet, Chapter 7:Unit7.20. 2013.

15. Choi $Y$, Chan AP. PROVEAN web server: a tool to predict the functional effect of amino acid substitutions and indels. Bioinformatics. 2015; 31(16):2745-7.

16. Kumar P, Henikoff S, Ng PC. Predicting the effects of coding non-synonymous variants on protein function using the SIFT algorithm. Nat Protoc. 2009; 4:1073-81.

17. Schwarz JM, Cooper DN, Schuelke M, Seelow D. MutationTaster2: mutation prediction for the deep-sequencing age. Nat Methods. 2014;11:361-2.

18. Escayg A, MacDonald BT, Meisler MH, Baulac S, Huberfeld G, AnGourfinkel I et al. Mutations of SCN1A, encoding a neuronal sodium channel, in two families with GEFS + 2. Nat Genet. 2000;24(4):343-5.

19. Witkowska-Olearska K. Epidemiology of vascular headache and migraine in the population of Warsaw. Neurol Neurochir Pol. 1975;9:495-502.

20. Szczudlik A. Migraine awareness, treatment, and education in Poland. Cephalalgia. 1998;18:65-6.

21. Vahedi K, Depienne C, Le Fort D, Riant F, Chaine P, Trouillard O et al. Elicited repetitive daily blindness:

a new phenotype associated with hemiplegic migraine and SCN1A mutations. Neurology. 2009;72:1178-83

22. Weller CM, Pelzer N, de Vries B, López MA, De Fàbregues O, Pascual J, et al. Two novel SCN1A mutations identified in families with familial hemiplegic migraine. Cephalalgia. 2014;34:1062-9.

23. Kahlig KM, Misra SN, George Jr AL. Impaired inactivation gate stabilization predicts increased persistent current for an epilepsy-associated SCN1A mutation. J Neurosci. 2006;26:10958-66.

24. Andres-Enguix I, Shang L, Stansfeld PJ, Morahan JM, Sansom MS, Lafrenière RG et al. Functional analysis of missense variants in the TRESK (KCNK18) K channel. Sci Rep. 2012;2:237.
25. Rainero I, Rubino E, Gallone S, Zavarise P, Carli D, Boschi S et al. KCNK18 (TRESK) genetic variants in Italian patients with migraine. Headache. 2014;54 1515-22.

26. Yu FH, Catterall WA. Overview of the voltage-gated sodium channel family. Genome Biol. 2003:4:207.

27. Intiso D, Crociani P, Fogli D, Grandone E, Cappucci G, Di Rienzo F et al. Occurrence of factor $V$ Leiden mutation (Arg506Gln) and anticardiolipin antibodies in migraine patients. Neurol Sci. 2002;22:455-8.

28. Soriani S, Borgna-Pignatti C, Trabetti E, Casartelli A, Montagna P, Pignatti PF et al. Frequency of factor $V$ Leiden

in juvenile migraine with aura. Headache. 1998:38:779-81.

29. Brackenbury WJ, Isom LL. Na channel $\beta$ subunits: overachievers of the ion channel family. Front Pharmacol. 2011;28(2):53.

\section{Submit your next manuscript to BioMed Central and we will help you at every step:}

- We accept pre-submission inquiries

- Our selector tool helps you to find the most relevant journal

- We provide round the clock customer support

- Convenient online submission

- Thorough peer review

- Inclusion in PubMed and all major indexing services

- Maximum visibility for your research

Submit your manuscript at www.biomedcentral.com/submit
) Biomed Central 